\title{
Learning the Narrative Characteristic: Perspective Taking in Written Japanese as a Foreign Language
}

\author{
Akiko Kashiwagi-Wood \\ Department of Modern Languages and Literatures, Oakland University, Michigan, U.S.A.
}

\begin{abstract}
Narratives written by $\mathrm{L} 2$ learners are often awkward even after linguistic elements such as grammatical errors and vocabulary choices are corrected. This unnaturalness may be caused by not exploiting the appropriate cultural and language specific aspects in the target language. The current study focuses on a narrative characteristic of Japanese; perspective taking consistency in writing a story, and the uses of its associated structures. By examining intermediate L2 learners of Japanese whose L1 is English, this study seeks to prove whether classroom instruction helps to overcome unnaturalness caused by the inappropriate uses of perspective taking and not using its associated structures in the short- and long terms. The results of this study show that instruction helps L2 learners to maintain the consistent perspective both in the short- and longterms. However, the instruction seems to have not affected the L2 learners' utilization of a variety of perspective taking structures. Taken together, this study offers implications for earlier instruction on the learning of the narrative characteristic.
\end{abstract}

Index Terms - L 2 writing, perspective taking, instruction, Japanese

\section{INTRODUCTION}

Narrating a story is essential to our social life. People tell stories about a description of actual or fictional events, and people tell stories to share their experiences or express their feelings (Johnstone, 2001). This activity is universal, but at the same time, it is one of the most challenging language activities for second language (L2) learners (Ellis, 1987; Robinson, 1995), because there are culture and language specific aspects in storytelling (Labov, 1972, 1997, 2006; Tannen, 1982). While unnaturalness in L2 storytelling may be caused by aspects such as grammatical errors and vocabulary choices, not appropriately exploiting the culture and language specific aspects can be quite obtrusive and should not be overlooked. However, this issue is not adequately taught in the formal language teaching setting.

There are many studies, which focus their investigations on the macro-level of L2 narratives. Many of these studies have undertaken L1 influence on narrative structures and coherence (e.g., Kang, 2003, 2006; Lee, 2003; McClure, Mir, \& Cadierno, 1993). The current study, however, focuses on the micro-level, particularly language specific linguistic elements that can also influence the macro-level in L2 narratives; namely perspective taking. The importance of perspective taking in storytelling has been discussed in the previous literature. For example, Slobin (2000) writes that "one cannot verbalize experience without taking a perspective, and, further, that the language being used often favors particular perspectives" (Slobin, 2000: 107). Perspective taking - also referred to as viewpoint and/or construal - shows individuals' physical and/or psychological standpoint in depicting an event and it also shows how individuals perceive, comprehend and interpret the world around them (Ikegami, 1982, 2011; Kuno, 1978). This indicates that each language has a specific way of incorporating perspective taking in its storytelling. For example, suppose you saw a boy knock over a flower vase and the vase ends up broken on the floor. In English, an agentive description such as "The boy broke the vase," is appropriate. In Japanese, on the other hand, the direct translation of the previous agentive English sentence would possess the tone of accusation towards the boy, assuming that he deliberately broke the vase. Thus, the agentive sentence may be inappropriate in Japanese, if the boy didn't have any intentionality to do so. To avoid the misunderstanding and in order to properly express the speaker's perspective of an event, one may take advantage of different structures, such as active and passive voices.

Keeping a particular perspective in storytelling, i.e., consistency of perspective taking, is considered one of the key factors in Japanese narratives. To do so, Japanese utilizes a variety of structures to keep the subject/agent constant. This is extremely important because Japanese is a pro-drop language, which allows certain classes of pronouns such as subject/agent to be omitted when they are pragmatically or grammatically inferable, and thus, inconsistency in perspective taking affects comprehensibility of the text (Ikegami, 1982). This narrative characteristic is not dominant in English since English prefers to change the subject/agent to keep the active voice throughout the story. The difference in narrative characteristics between the two languages poses mainly two challenges for English native speakers learning Japanese: the first is maintaining consistency in perspective taking throughout their story, and the second is learning and using appropriate grammatical structures to keep that perspective consistent. Considering this, the current study examines perspective taking in written storytelling by English native Japanese as a foreign language (L2 Japanese) 
learners, and further seeks to prove whether classroom instruction helps to overcome unnaturalness in L2 narratives.

\section{LITERATURE REVIEW}

\section{A. Perspective Taking in Japanese Narratives}

There are normally several ways to depict an event without altering its logical contents. For example, the following two sentences describe the same event. However, the perspectives from which they are depicted are different.

(1) The man offered a seat to the old lady.

(2) The old lady was offered a seat by the man.

Example (1) takes the perspective of 'the man' and depicts him as the active agent in the event. Example (2), on the contrary, takes the perspective of 'the old lady' and depicts her as the active recipient in the event. When Example (1) is translated into Japanese, the following sentence will be formed, which is perfectly grammatical, but not necessarily appropriate in a certain context.

(3) Otokonohito-ga obaasan-ni seki-o yuzutta.

Man-NOM $^{1}$ old lady-DAT seat-ACC offered

'The man offered a seat to the old lady.'

In Japanese, whether the speaker feels psychologically closer to the man or to the old lady, or is simply depicting an event objectively and not taking any side, influences the sentence structure. For example, Example (3) is an instance of an objective statement. The speaker is not psychologically close to, or not acquainted, with the man nor the old lady, and that can be understood from the verb, yuzutta 'offered' without any auxiliary verbs attached to it. On the other hand, Examples (4) and (5) with the benefactive auxiliary verbs, '-te ageru' and '-te kureru', respectively, express the speaker's 'empathy' towards the persons involved in the event.

(4) Otokonohito-ga obaasan-ni seki-o yuzutte-ageta.

Man-NOM old lady-DAT seat-ACC offer-gave (to someone/out-group).

'The man offered a seat to the old lady (and what a nice thing he did for the old lady).'

(5) Otokonohito-ga obaasan-ni seki-o yuzutte-kureta.

Man-NOM old lady-DAT seat-ACC offer-gave (to me/in-group).

'The man offered a seat to the old lady (and I thank him for doing that for her).'

Kuno \& Kaburaki (1977), followed by Kuno (1987), proposed the idea of empathy in Japanese. According to them, one chooses to place oneself in relation to the elements involved in a sentence when depicting an event in Japanese. That is, the speaker chooses a 'camera placement' about where to place oneself with respect to the events. What is expressed in the parentheses in Examples (4) and (5) are the representations of the speaker's empathy. In other words, the speaker is choosing the specific 'camera placement' to show the 'empathy' towards the man in Example (4) and the speaker is showing the 'empathy' towards the old lady in Example (5). The benefactive auxiliary verbs -te ageru (give benefit to someone else/out-group) and -te kureru (give benefit to me/in-group) are one of those structures that express the speaker's 'empathy' towards people or things in an event, and in the case of storytelling, they imply camera placement, i.e., taking a perspective from which the story is told.

Various structures are associated with articulating 'empathy' and perspective in Japanese narratives. As discussed previously, the benefactive auxiliary verbs -te kureru (give benefit to me/in-group), -te ageru (give benefit to someone else/out-group) and -te morau (receive benefit to me/in-group) are frequently used to indicate how one perceives or feels about an event. Additionally, moving verbs and moving auxiliary verbs (-te iku 'move away', -te kuru 'come towards'), passive voice, as well as subjective and emotional expressions can be utilized in storytelling to indicate consistency in perspectives (Ikegami, 1982, 2011; Kuno, 1978, 1987; Kuno \& Kaburaki, 1977).

\section{B. Perspective Taking in L2 Japanese}

Previous L2 Japanese studies, which were conducted to explore this topic, have found that L2 learners tend to have inconsistencies in perspective taking when writing a story (e.g., Kim, 2007; Okugawa, 2007; Sakamoto, Kang \& Moriwaki, 2014; Tashiro, 1995; Wei 2010a, 2010b). For example, Okugawa (2007) compared written narratives produced by intermediate and advanced level Chinese native L2 learners of Japanese and Japanese native speakers. Using a British-Swiss silent animation, Pingu the Penguin, the participants were asked to write a story based on what they have watched. The analyses focused on what was being depicted and from which perspective the event was depicted. What was found from Okugawa's analyses are that the native speakers kept the perspective consistent whereas the intermediate and advanced level learners did not when writing a story.

Many of the previous L2 Japanese studies examined Asian first language (L1) learners of Japanese as their participants. However, there are a few studies, which included L1 English learners as their participants and obtained similar results. For instance, Yabuki-Soh (2017) examined intermediate high and advance level L2 learners of Japanese studying at a Canadian university. The participants were 15 each from Chinese L1, Korean L1 and English L1 and compared their writings with those of native speakers. Using a 10-panel comic strip, which had several characters who

${ }^{1} \mathrm{ACC}=$ Accusative case, $\mathrm{DAT}=$ Dative case, $\mathrm{NOM}=$ Nominative case, $\mathrm{TOP}=$ Topic marker 
could have been an agent of sentences, her study again showed that the native speakers tended to tell a story from one character's perspective whereas L2 learners tended to write a story from the perspective of an active participant of the action in the event, regardless of their L1.

Although these previous studies have not conducted statistical analyses, they provide useful insights. That is, Japanese native speakers tend to write with consistent perspective. On the contrary, L2 learners of Japanese tend to demonstrate inconsistency in perspective even at advanced proficiency level regardless of their L1. These outcomes may be due to the lack of instruction on cultural and language specific characteristics in Japanese narratives. For this reason, we will now look at the previous L2 Japanese studies, which examined the effect of instruction on perspective consistency.

To the extent of my knowledge, only a few studies investigated the effect of instruction on the use of perspective expressions and its consistency in storytelling. These studies do not necessarily provide in depth descriptions of what their 'instruction' entails. However, they do seem to call 'instruction' something that they tell participants to do at the time of data collection and not necessarily class time dedicated for teaching and practicing. A study by Watanabe (2012) examined the effect of instruction on the uses of perspective expressions in intermediate and advanced L2 Japanese learners with various L1 (Chinese, Korean, Mongolian, Burmese, Malaysian). Watanabe divided the participants into 4 groups: 1) instruction group: 23 learners studying Japanese at a university in Japan, and 2) no-instruction group: 11 learners studying Japanese in Japan, and 3) no-instruction group: 15 learners studying Japanese in China, and 4 ) 47 Japanese native college students. Similarly to Okugawa (2007), Watanabe used the British-Swiss silent animation, Ping $u$ the Penguin, and asked the participants to write the story they watched. The participants of the instruction group were informed that Japanese requires consistency in perspective taking when telling a story, and in order to do so, keeping the same subject/agent is necessary. The participants were also informed that different types of sentences, specifically passive voice and benefactive auxiliary verbs, can be used to indicate and control perspectives. At the time of data collection, the instruction group was told to write the story from the main character (Pingu)'s perspective. There were no statistical analyses conducted for this study, but with no surprise, the results indicated that the instruction group showed more coherent subject/agent chains. As for the two specific perspective structures, the instruction group overly used passive voice, but the frequencies of benefactive auxiliary verbs between the instruction and no-instruction groups seemed to not be as different from one another.

Another research by Wei $(2010 \mathrm{a}, 2010 \mathrm{~b})$ conducted a study using a comic strip and examined perspective consistency in the story writing of intermediate and advanced level Taiwanese learners of Japanese and compared it with Japanese native speakers. Wei divided the participants into two groups each for intermediate and advanced proficiency levels and Japanese native speakers (6 groups total; 1instruction group each in intermediate, advanced and native, 1 no-instruction group each in intermediate advanced and native). The no-instruction groups were simply asked to describe the comic strip without any restrictions. The instruction groups were told to describe the comic strips as though they were one of the characters. From the analyses of the no-instruction groups, it was revealed that Japanese native group used more benefactive and movement structures than the intermediate and advanced learner groups. The no-instruction learner groups, on the other hand, used more emotional expressions. Comparing the instruction groups, similar to Watanabe (2012), Wei found that both intermediate and advanced instruction groups kept the same perspective throughout their stories, similarly to the native speaker group. Wei further found that the benefactive auxiliary verbs were rarely used by the intermediate group with instruction. However, the advanced group with instruction used a variety of perspective expressions more similarly to the native speaker group, including benefactive auxiliary verbs.

Both Watanabe (2012) and Wei (2010a, 2010b) showed that L2 learners of Japanese demonstrate perspective consistency in their storytelling when directed to do so. Furthermore, they illuminated that a simple instruction at the time of data collection is not enough for L2 learners to appropriately utilize the perspective taking structures. Particularly, the giving/receiving benefactive auxiliary verbs seem to cause a challenge for them. Although these studies compared instruction and no-instruction groups, it is important to reiterate that their focus was not on instruction. The instruction groups in these studies were told to write from a certain character's perspective at the time of data collection. With that in mind, it is no wonder that the instruction groups showed more consistency in perspective taking.

In sum, while there have been a number of studies on perspective consistency in L2 Japanese narratives, there still remain areas to explore. Firstly, despite the fact that the structures associated with perspective taking in Japanese are introduced in beginner level textbooks, the previous studies mainly investigated the performance of higher proficiency level learners. By the time L2 learners of Japanese enter the intermediate proficiency level, they already have the knowledge of the necessary sentence structures, if not mastered, for articulating perspective consistency in their narratives. The American Council on the Teaching of Foreign Languages (ACTFL), which is a premier national organization for foreign language teachers in the U.S., states in their proficiency rating criteria that L2 learners at Intermediate High level "can narrate and describe in different time frames when writing about everyday events and situations" (ACTFL Proficiency Guidelines 2012, Writing). That means L2 learners will need to learn the language specific narrative characteristics to achieve the Intermediate High or higher level of proficiency. Thus, more studies examining the performance of intermediate level learners are required. Secondly, based on the findings from extensive L2 research, it is now widely accepted that instruction indeed influences the L2 learning process (e.g., Doughty, 2003; 
Ellis, 1994; Spada, 1986). Therefore, it is important to shed light on the effectiveness of 'classroom' instruction and its long-term effect on the current issue. And lastly, only a limited amount of research has been done on L2 learners whose L1 is English, and it is important to have more non-Asian language background learners to provide more comprehensive understanding. All taken together, the current study addresses these shortcomings by examining stories written by English native L2 learners of Japanese whose proficiency level are at the intermediate level. Furthermore, the short-term and long-term effect of classroom instruction on their uses of perspective consistency will be explored.

\section{METHOD}

The focus of this paper is two-fold; the first objective is to investigate whether intermediate level L2 learners of Japanese, whose L1 is English, demonstrate consistency in perspective taking and use its associated structures in writing a story. The second objective is to report the short- and long-term effect of instruction on consistency in perspective taking and its associated structural uses. The research questions of the study are the following:

1. Do L2 learners demonstrate consistent perspective or inconsistent/neutral perspective in writing a story and does classroom instruction have any short- and long-term effect on it?

2. Do L2 learners utilize a variety of structures associated with perspective taking and does classroom instruction have any short- and long-term effect on the uses of the structures?

\section{A. Participants}

There were two participant groups: an instruction group and a no-instruction group. These participant groups belonged to two different sections of the same course at a university in the U.S. ${ }^{2}$ For the instruction group, the participants were $14 \mathrm{~L} 2$ learners and their length of study varied between 2.5 to 6 years. Among the 14 participants, three of the learners took Japanese in high school. The age range was 19-26 years old and all of them were English native speakers. For the no-instruction group, originally, there were 15 L2 learners who were asked to participate, but one learner did not submit the writing. Therefore, the writings of 14 L2 learners were analyzed as the data for the noinstruction group. Their length of study varied between 2.5 to 6 years with two learners who took Japanese in high school and one learner who participated in a semester study abroad program. The age range was 19-33 years old and all of them were English native speakers. The participants' background data was collected as a part of a classroom survey at the beginning of their language courses. Based on the content of the textbook for their language courses and the number of hours of classroom instruction, these participants are considered to be at the intermediate level of language proficiency (refer to ACTFL Proficiency Guidelines 2012 and the ACTFL Performance Descriptors for Language Learners the Can-Do Statements).

\section{B. Material}

The data was collected using a written storytelling task using an 8-panel comic strip, which was adopted from Wei (2010a, 2010b). The 1st panel had two boys. One boy (A) is sweeping outside his house and the other boy (B) is stopping by at the boy (A)'s house by bicycle. The boy (A) notices the boy (B). The 2nd panel shows that the boy (A) walks toward the boy (B) and talks to him. The 3rd panel shows the boy (A) points to the boy (B)'s bicycle. The 4th panel shows the boy (A) riding the boy (B)'s bicycle. The 5th panel shows the boy (A) is going down on the hill on the bicycle very fast and the 6th panel shows him crashing into a tree. The 7th panel shows the boy (B) is mad at the boy (A) for crashing and breaking his bicycle. The 8th panel shows the boy (B) treating the boy (A)'s injury from the crash.

This 8-panel comic strip was chosen because it had only two characters, which restrict the perspective that the writer can take and it involved a clear incident of crashing a bicycle into a tree. The panels also trigger certain structures under question, such as come and go movement expressions (e.g., asobi ni-kuru 'to pay a visit; to stop by') and benefactive auxiliary verb structures (e.g., kashite-ageru 'to lend'), that participants may utilize in their writing. The participants were told to write a story based on the comic strip, without any explanation of the study's intent. This task was an assignment for both instruction and no-instruction groups. The participants used 400-character boxed writing sheets, which is typically used in Japanese writing classes. For the instruction group, the same comic strip was used for the 1st and 2 nd data collections, and prior to the 1st data collection, classroom instruction was provided. There was no feedback given to the instruction group after the 1st writing.

\section{Instruction}

For the instruction group, two class sessions (approximately 50 minutes each) were dedicated to introducing and practicing the perspective taking and its associated structures in Japanese storytelling, which occurred before the 1st data collection (=1st writing). As mentioned previously, the sentence structures had been introduced in the participants' beginner course textbooks. Thus, the participants were already exposed to those structures and had practiced through textbook exercises and classroom activities, but not as the way of exploiting Japanese narrative characteristics. The two instruction sessions employed Focus-on-Form approach, which allowed the learners to notice and raise awareness of the different ways to express perspectives as well as the importance of the consistency in perspective taking in Japanese

\footnotetext{
${ }^{2}$ The course was the $2^{\text {nd }}$ semester course of the $3^{\text {rd }}$ year college Japanese.
} 
storytelling. More specifically, in the first session, the instruction involved pictures which can be depicted using one of the perspective taking structures. Due to the results from the previous studies indicating that L2 learners have difficulty utilizing benefactive auxiliary verbs and passive voice, the session focused mainly on those two types of structures. During the session, the participants orally practiced the sentence patterns using illustrations. Then, they were given situations accompanied by a dialogue with fill in the blanks. They were asked to work in a pair or a group to complete each dialogue and practice together. Feedback was provided throughout the session. In the second session, two texts one with consistent perspective with structures such as benefactive, come and go movement, and the other with inconsistent perspective with active voice sentences - were provided to the participants to read and compare the differences. This activity was designed so that it provoked awareness to the characteristics of Japanese storytelling. In particular, the participants were asked to underline the parts they thought were different, and later discussed their influences on the comprehensibility of the text and its naturalness. English language was used as the means of communication for this activity. Lastly, the second session was concluded with writing a story using a well-known Japanese 4 panel-comic strip called 'Sazae-san' and sharing the story with their classmates. Feedback was provided by pointing out the appropriate uses of the sentence structures and consistency in perspective taking. The two instruction sessions were one week apart.

\section{Data Collection}

For the instruction group, the first data was collected when the participants had equivalent of approximately 180 hours of classroom instruction and immediately after the second instruction session (1st writing). Approximately six weeks after, the same $14 \mathrm{~L} 2$ learners participated in the second data collection, which was done using the same 8-panel comic strip (2nd writing). For this 2nd data collection, the participants were just given the same 8-panel comic strip and were instructed to write a story based on the comic strip. No specific instruction, such as a direction to write a story from a specific character, was given. The same comic strip was chosen for the 2nd data collection because it allows direct comparisons between the two writings. For the data collection of the no-instruction group, the participants had approximately 200 hours of classroom instruction when their writings were collected. They were given the same comic strip as the instruction group as an assignment and were simply told to write a story based on it.

\section{E. Procedure for Analyses}

The participants' writings were collected and examined as the data. Based on the previous studies (e.g., Ikegami, 1982; Kuno, 1978; Wei, 2010b), the analyses focused on five different sentence structures associated with perspective taking in Japanese (Table 1). For analyses, first, these expressions were underlined and counted in the participants' writings. Then, whether there is consistency in perspective taking throughout the story was determined by examining each of the perspective expressions used following the procedure described in Flowchart 1. Because the data was collected from L2 learners who are still in the midst of learning the language, the writing did not come error-free. Character (kanji) errors, minor conjugation and particle errors were not considered to hinder the purpose of this study. However, when topic and case particle errors occurred in the same sentence with the perspective taking expressions, they were excluded from the further analyses.

TABLE 1.

PERSPECTIVE EXPRESSIONS EXAMINED

\begin{tabular}{|c|c|}
\hline Expressions & Actual learner examples \\
\hline $\begin{array}{l}\text { Benefactive } \\
\text { kureru 'give to me' / ageru 'give to someone'/ morau 'to receive'/ } \\
\text { te kureru 'someone does X for me'/ } \text { te ageru 'someone does X } \\
\text { for someone else' / te morau 'have someone to do X for me' }\end{array}$ & $\begin{array}{l}\text { Takeshi-wa otousan-ni atarashii jitensya-o katte moratta node... } \\
\text { Takeshi-TOP father-DAT new } \text { bicycle-ACC received buying } \\
\text { 'Because... } \\
\text { 'Because Takeshi received a new bicycle from his father...., }\end{array}$ \\
\hline $\begin{array}{l}\text { Come/go } \quad \text { movement } \\
\text { kuru 'come' / iku 'go' / te iku 'go doing something' / te kuru } \\
\text { 'come doing something' }\end{array}$ & 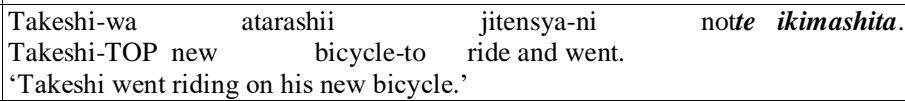 \\
\hline $\begin{array}{l}\text { Passive } \\
\text { Verb + -rareru / -areru 'to be }+ \text { past participle' }\end{array}$ &  \\
\hline $\begin{array}{l}\text { Subjective } \\
\text { omou 'think' / wakaru 'to comprehend/understand' / kangaeru 'to } \\
\text { consider/think' / kanjiru 'to feel' / kizuku 'to notice' }\end{array}$ & $\begin{array}{l}\begin{array}{l}\text { Satoshi-wa atarashii } \quad \begin{array}{l}\text { jitensya-ni } \\
\text { bicycle-at }\end{array} \\
\text { Satoshi-TOP new } \\
\text { 'Satoshi noticed a new bicycle.' }\end{array} \\
\end{array}$ \\
\hline $\begin{array}{l}\text { Emotional } \\
\text { ureshii 'be glad' / hoshii 'to want' / odoroku 'to be amazed or } \\
\text { astonished'/ bikkuri-suru 'to be surprised' / tai 'want to X' }\end{array}$ & 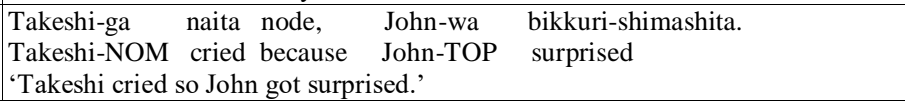 \\
\hline
\end{tabular}




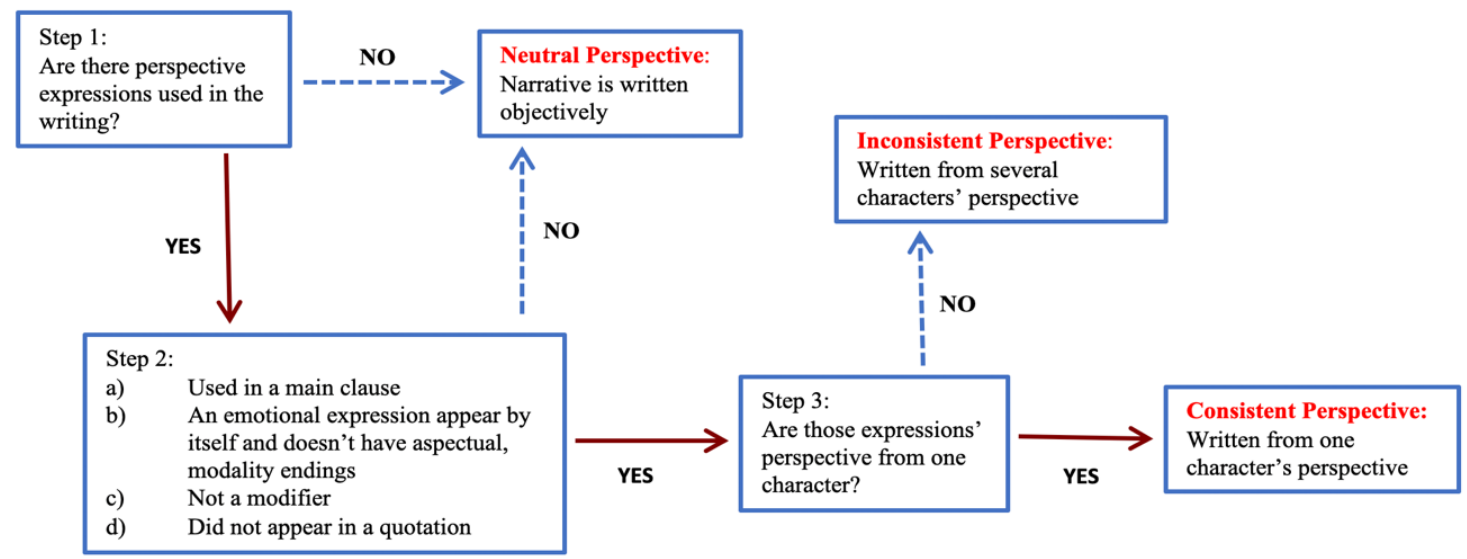

Flow Chart 1.

Steps for Deciding Consistency in Perspective Taking (adopted from Wei, 2010a)

\section{F. Results}

One of the research questions addressed in this study was whether the intermediate L2 learners demonstrate consistent perspective or non-consistent (inconsistent and neutral) perspective in their stories and whether instruction has any influence on it. The results of perspective taking consistency in L2 writing is shown in Table 2 and Graph 1 . As can be seen, the instruction group used more consistent perspectives in both the 1st and 2nd writings whereas the noinstruction group demonstrated a clear tendency of non-consistent perspectives in their story writings.

TABLE 2.

PERSPECTIVE TAKING IN L2 WRITING

\begin{tabular}{|c|c|c|c|c|c|}
\hline \multicolumn{2}{|c|}{ Groups } & Consistent & Inconsistent & Neutral & Total \\
\hline \multirow{2}{*}{$\begin{array}{c}\text { Instruction } \\
(\mathrm{n}=14)\end{array}$} & 1st Writing & $9(64 \%)$ & $3(21 \%)$ & $2(14 \%)$ & 14 \\
\cline { 2 - 6 } & 2nd Writing & $10(71 \%)$ & $3(21 \%)$ & $1(7 \%)$ & 14 \\
\hline \multicolumn{2}{c|}{$\begin{array}{c}\text { No-instruction } \\
(\mathrm{n}=14)\end{array}$} & $3(21 \%)$ & $11(79 \%)$ & $0(0 \%)$ & 14 \\
\hline
\end{tabular}

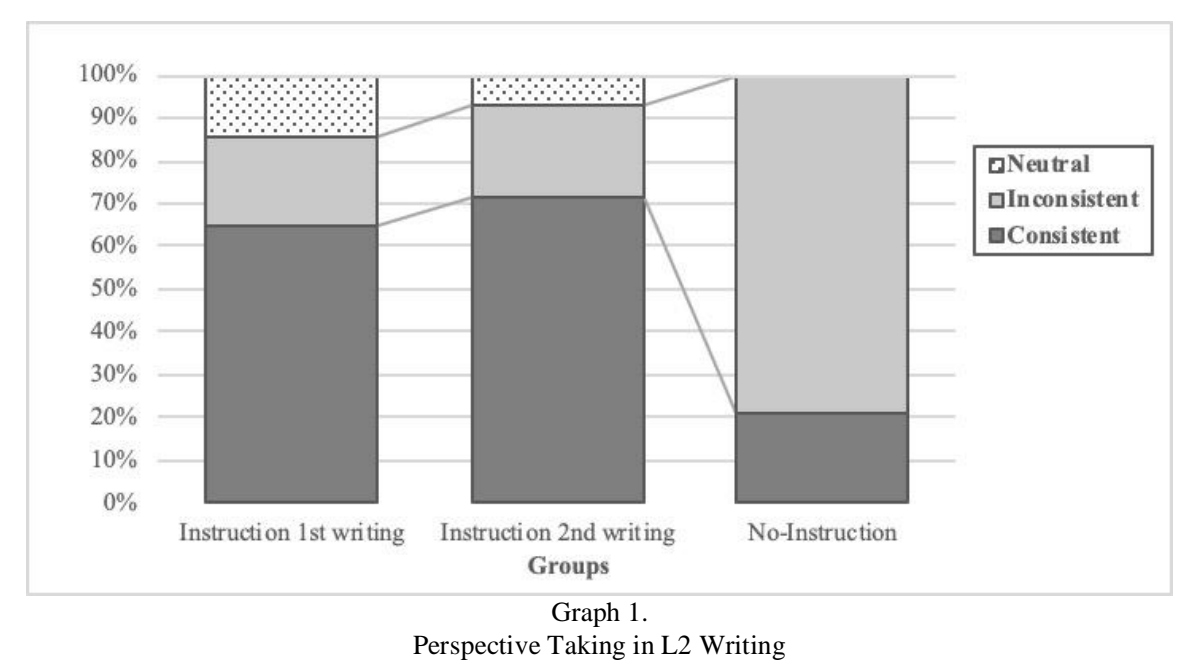

The chi-square test of independence was performed to examine the relation between instruction and perspective taking; more specifically, between the 1st writing of instruction and no-instruction groups and consistent and nonconsistent (inconsistent + neutral) perspectives. The relation between these variables was significant, $\chi 2(1)=5.25, p<$. 05 . The same test was performed with the 2 nd writing of instruction and no-instruction groups and consistent and nonconsistent (inconsistent + neutral) perspectives and it was also significant, $\chi 2(1)=5.1692, p<$. 05 . Next, whether the instruction group's participants have taken consistent perspectives for both the 1st and 2nd writings or switched between consistent and non-consistent perspectives was examined. A McNemar's test determined that there was no 
statistically significant difference in the proportion of consistent perspective taking between the 1 st and 2 nd writings, $p$ $=.72$. These results combined together imply that the classroom instruction is effective not only in the short-term, but also in the long-term in case of learning the consistency in perspective taking in L2 Japanese narratives.

Another research question addressed in this study was to examine whether the intermediate L2 learners utilize a variety of structures associated with perspective taking and whether instruction has any influence on the frequency of their appearances in L2 learners' written stories. Table 3 demonstrates five types of perspective taking structures used in the written data. As Table 3 indicates, the instruction group used more perspective taking structures in their 1 st and 2 nd writings compared to the no-instruction group. T-tests were administered and it was found that the 1st writing of the instruction group $(\mathrm{M}=7.36, \mathrm{SD}=3.10)$ demonstrated significantly more occurrences of perspective taking sentences compared to the no-instruction group $(\mathrm{M}=4.57, \mathrm{SD}=2.47), t(13)=2.627, p<.05$. However, no significance was observed between the 2 nd writing of the instruction group $(\mathrm{M}=6, \mathrm{SD}=3.44)$ and the no-instruction group $(\mathrm{M}=4.57, \mathrm{SD}$ $=2.47), t(13)=1.2614, p>.1$.

TABLE 3

TYPES OF PERSPECTIVE TAKING STRUCTURES USED IN L2 WRITING

\begin{tabular}{|l|l|l|l|l|l|l|l|}
\hline \multicolumn{2}{|l}{} & & & & & \\
Groups & Benefactive & $\begin{array}{l}\text { Come/go } \\
\text { movement }\end{array}$ & Passive & Subjective & Emotional & Total \\
\hline \multirow{2}{*}{$\begin{array}{l}\text { Instruction } \\
(\mathrm{n}=14)\end{array}$} & 2nd Writing & $16(15 \%)$ & $20(19 \%)$ & $6(6 \%)$ & $13(13 \%)$ & $48(47 \%)$ & 103 \\
\hline & 2nditing & $14(17 \%)$ & $12(14 \%)$ & $21(25 \%)$ & $8(10 \%)$ & $29(34 \%)$ & 84 \\
No-instruction $(\mathrm{n}=14)$ & $16(25 \%)$ & $14(22 \%)$ & $1(1 \%)$ & $5(8 \%)$ & $28(44 \%)$ & 64 \\
\hline
\end{tabular}

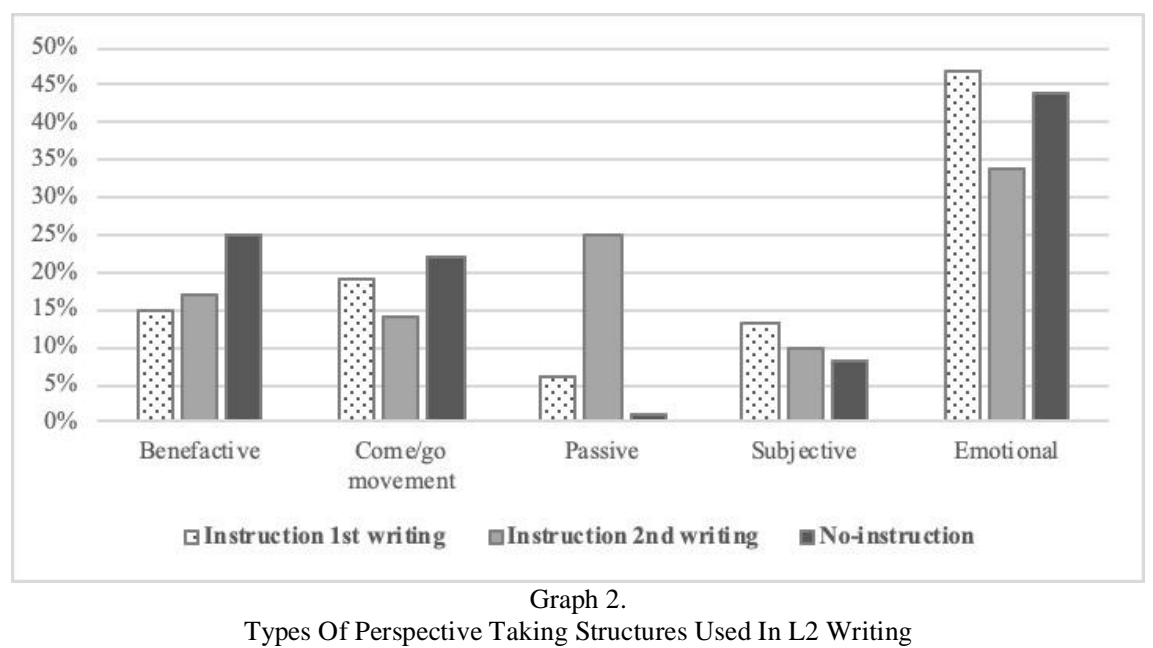

Looking at the individual structures, the frequencies of structures that the learners used seem similar between the instruction and non-instruction groups (Graph 2). A closer look at the percentages of each type of structures used indicate that emotional expressions are incorporated the most frequently into their stories, but the frequency of the other structures seem to be about the same.

To examine whether there was any statistical difference between the instruction and no-instruction groups in using the five perspective taking structures, Chi-square tests were conducted. No significance was found between the 1st writing of the instruction group and no-instruction group. On the other hand, there was a significant difference between the 2 nd writing of the instruction group and no-instruction group, $\chi 2(4)=26.9597, p<.05$. The residual analyses showed that the difference was found in the passive structure $(p<.01)$. Next, the perspective structures used in the 1st and the 2nd writings within the instruction group were compared. Due to the low size of $n(n=14)$, Wilcoxon SignedRank tests were performed for each structure and $W$-value was used to evaluate the hypotheses. From the analyses, a significant difference was only found in the uses of passive structure between the 1 st and the 2 nd writings, $W(14)=0, p$ $<.05$. Given these results, it seems that there is an immediate effect of instruction on the overall numbers of perspective taking structures used, but that effect of instruction is not retained for the long-term. Furthermore, the results indicate that the instruction does not seem to have a substantial influence on the types of perspective taking structures that the learners use.

\section{Discussion AND CONCLUSION}

This study explored the use of a narrative characteristic - consistency in perspective taking - by L2 learners of Japanese at the intermediate level of proficiency. Additionally, it attempted to investigate the short-term and long-term influence of classroom instruction to overcome the unnaturalness caused by its inappropriate uses, and investigated the 
effect of classroom instruction on diversified uses of five types of structures associated with perspective taking in L2 Japanese storytelling.

Examining the L2 learners' written stories, the results of this study yielded several findings. From the previous studies with advanced Asian L1 learners of Japanese, it has been demonstrated that without instruction, L2 learners have difficulty achieving the perspective consistency. By examining English native learners of Japanese at the intermediate level, the current study adds more evidence to much needed L2 studies on this topic. That is, the consistency in perspective taking in a storytelling is also difficult to acquire for English native L2 learners Japanese without explicit instruction.

A noteworthy finding from the current study is that instruction undoubtedly helped the intermediate level L2 learners to learn the narrative characteristic of perspective consistency not merely in the short-term, but also in the long-term. This finding is delightful news for both L2 learners and language teachers. Perspective consistency affects the comprehensibility of narratives (e.g., Wei, Tamaoka, \& Yamato, 2012). That means, whether it is a fictional story or a personal anecdote, in order for L2 learners to be able to communicate effectively and efficiently in Japanese, they need to know and utilize consistency in perspective taking in their L2 performance. The fact that perspective consistency was achieved by only two instructional sessions, it is very promising for foreign language teachers and learners when they consider the outcome of their teaching and the time spent for learning. Simply stated, spending time to instruct the narrative characteristic from the earlier stages of L2 learners' target language development would not end in vain; rather, it assists them to reach more-native like performance quicker.

Notwithstanding the positive influence of instruction on the topic matter, L2 learners still encounter its difficulty and complexity in exploiting diverse perspective expressions in their L2 narratives. Despite the effect of instruction observed in the total number of perspective taking structures integrated into the L2 learners' stories in the short-term, contrary to our expectations, it was not observed after 6 weeks. Moreover, the analyses of the different structures used in the L2 learners' writings showed that the utilization of a variety of perspective taking expressions is difficult at the intermediate proficiency level. A similar finding was noted in the previous studies as well. For instance, the acquisition of the benefactive auxiliary verbs, in general, has been discussed as one of the more challenging structures for any L2 learners of Japanese to acquire (e.g., Aramaki, 2003; Hagiwara, 2007; Sakamoto \& Okada 1996; Yun, 2004). In conjunction with perspective taking in L2 Japanese studies, the previous research such as Watanabe (2012) and Wei (2010a, 2010b) showed that the use of benefactive auxiliary verbs is more challenging than the other sentence types. It was indeed the case with the L2 learners of the current study, too. The benefactive auxiliary verbs were challenging for the L2 learners to incorporate and statistical significance was not found between the instruction and no-instruction groups. The only statistical significance observed was with the passive structure between the 1st writings of the instruction group and their 2nd writings, and between 2nd writings of the instruction group and no-instruction group's writings. To seek the cause of these significances, a closer inspection of each of the passive sentences on the 2 nd writings of the instruction group was undertaken.

There were quite a few occurrences of passive sentences in the 2 nd writings by the instruction group. Twenty-one passive structures (out of 84 overall perspective structures) were observed. Examining them more closely, it was revealed that the uses of these passive sentences in the 2nd writings are associated with two specific verbs; iwaremashita 'was told' and okoraremashita 'was scolded' (10 occurrences and 7 occurrences out of 21 occurrences, respectively). This is likely to indicate that L2 learners have not necessarily learned the passive structure as one of their choices for perspective taking consistency, rather, it is more natural to assume that they have associated these two verbs with this particular structure - passive - through the exposure to the language between the 1st and 2nd data collections, which were approximately 6 weeks apart. Therefore, at this moment, it is reasonable to presume that the L2 learners became more familiar and more comfortable with these two specific verbs in the passive structure, which lead to the higher frequency of occurrences in their 2nd writings.

The findings from the current study suggest that instruction is effective for learning perspective taking consistency in Japanese narratives, but it is not as effective for learning to utilize a variety of the associated structures. Why didn't the instruction facilitate the learning and the using of a variety of perspective taking structures? To provide a viable answer to this question, we will need to think about the complexity of learning these structures and using them as a perspective taking expression in storytelling.

The concept of keeping perspective consistent is likely to be not that challenging for L2 learners. Like the previous L2 studies, a few of which instructed their participants to write a story from a certain character's perspective, a simple instruction of Japanese narrative characteristic, i.e., consistency in perspective taking in storytelling, might be all L2 learners need. In a way, one can acquire this narrative characteristic by learning the concept as one of the rules in Japanese language. As long as L2 learners keep the rule in their mind and write from the perspective of the same subject/agent, the consistency of perspective taking in their story can be achieved.

Learning and using a variety of perspective taking structures in L2 storytelling, on the other hand, is more complex and demanding. Needless to say, that L2 learners first have to learn each form (grammar), but they also have to learn when and how to use them appropriately within the language and culturally specific narratives (pragmatic/discourse). Ellis (2006) has described language acquisition as "contingency learning, that is the gathering of information about the relative frequencies of form-function mappings" ( $p$. 1). If so, it can be considered that at the intermediate proficiency 
level, the exposure to these structures in L2 narratives is still lacking even after the instruction. In other words, limited instructional influences on the uses of perspective taking structures in the L2 learners' writings in this study may have been derived from the lack of exposure and the difficulty of form-function mapping. To make L2 learners to become more comfortable with incorporating the various perspective taking structures, an instructional method such as Focus on Form Task-Based instruction, which engages learners to induce form-function mapping, may be feasible (Ellis, 2003, 2016). Future research should focus on different instructional approaches to measure its effectiveness as well as more diverse backgrounds of learners.

In closing, consistency in perspective taking and its associated structures shape both micro- and macro-levels of Japanese narrative. Relying on inductive approaches to learn a narrative characteristic of L2 carries a risk that L2 learners may never notice or fully understand a preferred way of telling a story in the target language culture. Although there are limitations to this study, it has provided useful insights into learning and teaching of narrative characteristics for English native L2 learners at the intermediate level of proficiency. The fact that there was a positive influence of instruction on the learning of perspective taking consistency supports that the instruction of narrative characteristics need not, or perhaps should not, be reserved for advanced proficiency level learners. As well, providing instruction from the early stages of L2 learners' language development on different types of perspective taking structures certainly helps to build a foundation of conscious awareness and understanding, which will lead to more exposure, effective and efficient input and intake, and assists L2 learners to attain native-like language performance.

\section{ACKNOWLEDGMENTS}

The author wishes to thank Dr. Chih-Chen Wei for giving permission to use her comic strip for the data collection.

\section{REFERENCES}

[1] American Council on the Teaching of Foreign Languages. (2012). ACTFL Proficiency Guideline 2012. https://www.google.com/search?client=firefox-b-1-d\&q=ACTFL (accessed 21/01/2021).

[2] National Council of State Supervisors for Languages (NCSSFL) -ACTFL Performance Descriptors for Language Learners the Can-Do Statements. (no date). https://www.actfl.org/resources/ncssfl-actfl-can-do-statements (accessed 21/01/2021).

[3] Aramaki, T. (2003). Jyujyubun keisei nouryoku to bamen handan nouryoku no kankei - shitsumonshi chousa ni yoru jyujyuhyougen no goyoubunseki kara. [Relationship between the sentence formation and scene judgment abilities --From the error analysis of benefactive expressions from a questionnaire survey]. Nihongo Kyōiku, 117, 43-52.

[4] Doughty, C. (2003). Instructed SLA. Constraints, compensation, and enhancement. In C. Doughty \& M. Long (eds.), The handbook of second language acquisition. Malden, MA: Blackwell, 256-310.

[5] Ellis, R. (1987). Second Language Acquisition in Context, Prentice Hall International.

[6] Ellis, R. (1994). The study of second language acquisition. Oxford: Oxford University Press.

[7] Ellis, R. (2003). Task-based language learning and teaching. Oxford: Oxford University Press.

[8] Ellis, R. (2006). Current Issues in the Teaching of Grammar: An SLA Perspective. TESOL Quarterly 40.1, 83-107.

[9] Ellis, R. (2016). Focus-on-Form: A critical Review. Language Teaching Research 20.3, 405-428.

[10] Hagiwara, A. (2007). "-te ageru" "-te kureru" "-te morau" no bunpōsei handan tesuto: gakushūsha no nihongo rishūreki tono kakawari ni oite [Grammatical judgement test of -te ageru, -te kureru, -te morau: based on the length of Japanese study of learners]. ICU Nihongo Kyōiku Kenkyū 4, 3-19.

[11] Ikegami, Y. (1982). Tekusuto to Tekusuto no Kōzō. In National Institute for Japanese Language and Linguistics (ed). Discourse Research and Pedagogical Applications 1, 7-42. http://doi.org/10.15084/00001835

[12] Ikegami, Y. (2011). Nihongo washa ni okeru $<$ konomareru iimawashi $>$ to shite no $<$ shūkanteki haaku $>$ [Subjective Construal' as Japanese Speakers' 'Fashion of Speaking']. Jinkou chinou gakkaishi 26.4, 317-322.

[13] Johnstone, B. (2001). "Discourse Analysis and Narrative.” In D. Schiffrin, D. Nannen, and H. Hamilton (eds.), The handbook of discourse analysis. Malden, MA: Blackwell, 635-649.

[14] Kang, J.Y. (2003). On the ability to tell good stories in another language: Analysis of Korean EFL learners' oral "frog story" narratives. Narrative Inquiry 13.1, 127-149. https://doi.org/10.1075/ni.13.1.05kan (accessed 1/03/21).

[15] Kang, J. Y. (2006). Producing culturally appropriate narratives in English as a foreign language: A discourse analysis of Korean EFL learners' written narratives. Narrative Inquiry 16.2, 379-407. https://doi.org/10.1075/ni.16.2.08kan (accessed $1 / 03 / 21)$.

[16] Kim, E. (2007). Shiten o gan'i suru hyōgen no nikkan taishō kenkyū - kankujin nihongo gakushūsha no jujuhyōgen, ukemi bun, kashikari hyōgen nado o daizai ni -' [Comparative study of Japanese - Korean expressions that imply perspectives -on the subject of giving and receiving expressions, passive sentences, lending and borrowing expressions, etc. by Korean learners of Japanese-]. Jisedai jinbun shakai kenkyū 3, Japan-Korea Next Generation Academic FORUM, 247-263.

[17] Kuno, S. (1978). The Grammar of Discourse. Tokyo: Taishukan Shoten.

[18] Kuno, S. (1987). Functional syntax: Anaphora, discourse and empathy. Chicago: University of Chicago Press.

[19] Kuno, S., \& Kaburaki, E. (1977). Empathy and syntax. Linguistic Inquiry 8.4, 627-672.

[20] Labov, W. (1972). Sociolinguistic patterns. Philadelphia, PA: University of Pennsylvania Press.

[21] Labov, W. (1997). Some further steps in narrative analysis. Journal of Narrative and Life History 7.14, $395-415$. https://doi.org/10.1075/jnlh.7.49som (accessed 1/03/21).

[22] Labov, W. (2006). Narrative pre-construction. Narrative Inquiry, 16.1, 37-45. https://doi.org/10.1075/ni.16.1.07lab (accessed $1 / 03 / 21)$

[23] Lee, M. P. (2003). Discourse structure and rhetoric of English narratives: Differences between native English and Chinese non- 
native English writers. Text \& Talk, 23, 347-368.

[24] McClure, E., Mir, M., \& Cadierno, T. (1993). What do you include in a narrative? A comparison of the written narratives of Mexican and American fourth and ninth graders. Pragmatics and Language Learning 4, 209-224.

[25] Okugawa, I. (2007). Viewpoints and Situations in Narrative Discourse. Tsukuba Journal of Applied Linguistics, 14, 31-43.

[26] Robinson, P. (1995). Task Complexity and Second Language Narrative Discourse. Language Learning 45.1, 99-144. https://doi.org/10.1111/j.1467-1770.1995.tb00964.x (accessed 1/03/21).

[27] Sakamoto, M., Kang, F., \& Moriwaki, T. (2014). The Actual Condition of "Visual stance Formation" in Narrative Description of The Japanese Learner in China. Bulletin of Faculty of Business Administration Tokoha University, 1 (1), 77-86.

[28] Sakamoto, T., \& Okada, H. (1996). On acquisition of Japanese benefactive verbs Academia; Journal of the Nanzan Academic Society, Literature and Language 61, 157-202.

[29] Slobin, D. I. (2000). Verbalized events: a dynamic approach to linguistic relativity and determinism. In S. Niemeier, R. Dirven (eds.), Evidence for Linguistic Relativity. John Benjamins, Amsterdam/Philadelphia, 107-138.

[30] Spada, N. (1986). The interaction between types of content and type of instruction: Some effects on the L2 proficiency of adult learners. Studies in Second Language Acquisition 8, 181-199.

[31] Tannen, D. (1982). Oral and literate strategies in spoken and written narratives. Language 58, 1-21.

[32] Tashiro, H. (1995). Chūjyōkyūu nihongo gakushūsya no bunsyō hyōgen no mondaiten - Fushizensa, wakarinikusa no gen'in o saguru. [Issues with sentence expressions for intermediate and advanced Japanese learners--Searching for causes of unnaturalness and incomprehensibleness.] Nihongo Kyöiku 85, 25-37.

[33] Watanabe, F. (2012). Expression of viewpoints in Japanese narrative sentences and their guidance. Bulletin of Graduate School of Social and Cultural Systems. Yamagata University 9, 51-58.

[34] Wei, C-C. (2010a). Jitai byōsha ni okeru taiwanjin nihongogakushūsha to nihongo bogo washa no shiten no hikaku - shiza no okikata ni chūmoku shite - [Comparison of viewpoints of Taiwanese learners of Japanese and native speakers of Japanese in describing the situation-Focusing on how to place the viewpoint-]. Kotoba to Bunka 11, 255-270.

[35] Wei, C-C. (2010b). Taiwanjin Nihongo gakushūsha no jitai byōsha ni okeru shiten no arawashikata - nihongo no jukutatsudo to no kanrensei [How to Express Perspectives in Depicting the Situation of Taiwanese Learners of Japanese - Relationship with Japanese Proficiency]. Nihongo Kyoiku 144, 133-144.

[36] Wei, C-C., Tamaoka, K., \& Yamato, Y. (2012). Effects of viewpoint consistency on reading a Japanese text. Studies in Language Sciences 11, 114-131.

[37] Yabuki-Soh, N. (2017). Expressions of Viewpoint in Written Narratives: Comparing L2 Learners and Native Speakers of Japanese. Journal CAJLE, 18, 90-112.

[38] Yun, H. (2004). Dai ni gengo toshite no nihongo no jyujyu dōshi shūtoku kenkyū gaikan - Shūtoku jyunjyo no kekka to kenkyū hōhō tono taiō ni syōten o atete - [A review of research into the acquisition of giving/receiving verbs in L2 Japanese: Explaining the acquisition order]. Gengo bunka to Nihongo Kyoiku, 168-181. http://purl.org/coar/resource_type/c_6501 (accessed 01/04/21).

Akiko Kashiwagi-Wood was born in Japan and received a B.A. from Tokyo University of Foreign Studies in Japanese (1999), and a M.A. in TESOL from University of Findlay (2001) and a M.A. and a Ph.D. in East Asian Languages and Literatures with specialization in Japanese linguistics from The Ohio State University (2003, 2011, respectively). She is currently an Associate Professor of Japanese at Oakland University in Rochester, Michigan. She is a co-author of "Issues in L2 Japanese sentence processing: Similarities/differences with L1 and individual differences in working memory" in Handbook of Japanese Psycholinguistics (De Gruyter Mouton, 2015). Her research interests are second language acquisition, applied linguistics and Japanese language pedagogy. Prof. Kashiwagi-Wood is a member of the Japanese Society for Linguistic Science, American Association of Teachers of Japanese, Japanese Teachers Association of Michigan and The Society for Teaching Japanese as a Foreign Language. 